\title{
Intraoperative digital single-operator cholangioscopy - extra-anatomical biliary access and insights into severe sclerosing cholangitis in a pediatric patient
}

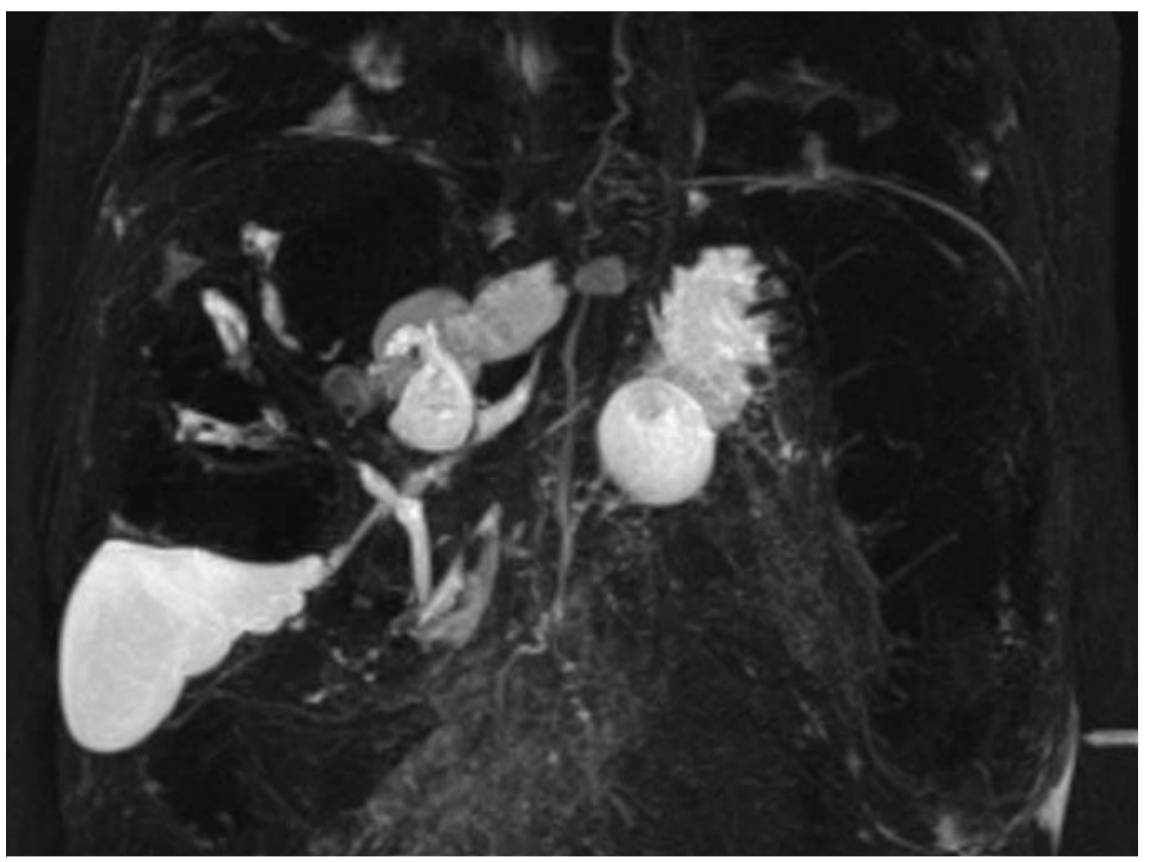

Fig. 1 Magnetic resonance imaging scan presenting cystic dilation of the biliary tract system.

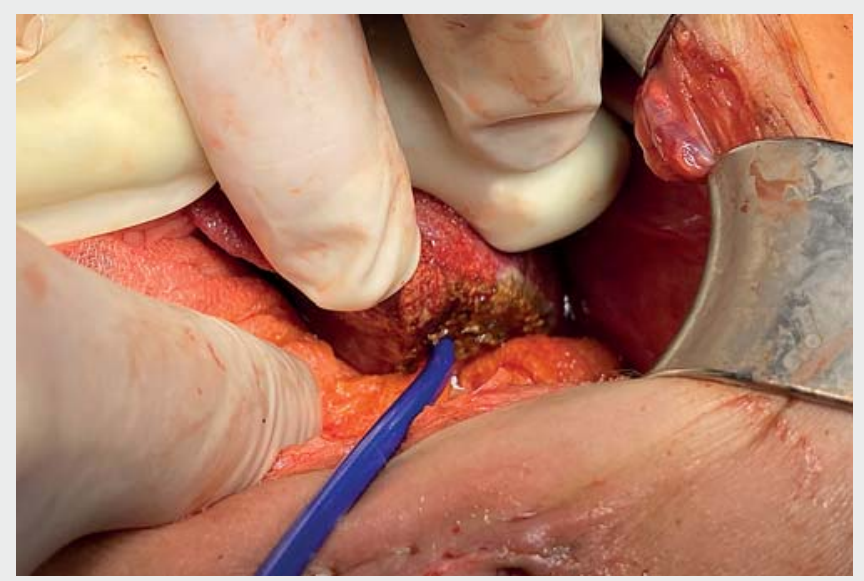

Video 1 Intraoperative cholangioscopy in a 3-year-old boy with severe sclerosing cholangitis.

A 3-year-old boy with Down's syndrome, born prematurely with atrial septal defect type II and stenosis of the pulmonary artery, presented with hepatopathy and fibrosis. Magnetic resonance imaging (MRI) showed diffuse dilations of the biliary system, with large cystic changes suspicious for Caroli syndrome ( $\mathbf{F i g} \mathbf{1}$ ).

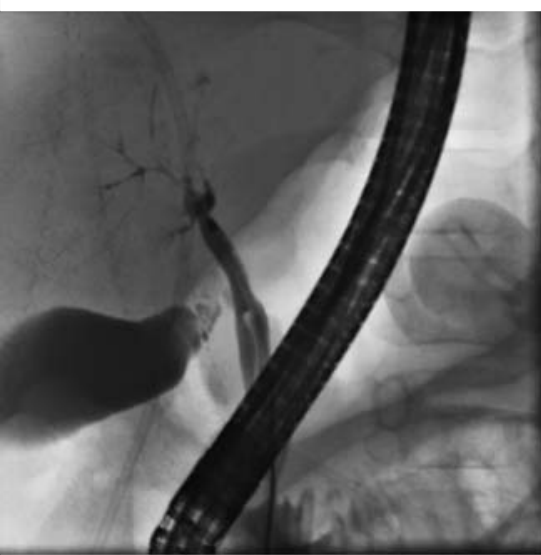

Fig. 2 Endoscopic retrograde cholangiography showing signs of secondary sclerosing cholangitis in the right biliary system.

Endoscopic retrograde cholangiography (ERC) presented signs of secondary sclerosing cholangitis of the right liver lobe with missing contrast enhancement of the left biliary system ( Because there was no communication of the left liver lobe with the central biliary system, the patient underwent surgery to drain the left liver lobe by peripheral hepaticojejunostomy. Access to the biliary system was gained by the open biliary system of segment II and intraoperative cholangioscopy was performed using the newly developed, short digital system (SpyGlass Discover; Boston Scientific Corp., Marlborough, Massachusetts, USA) (\Video 1, > Fig. 3). Intraoperative cholangioscopy revealed cystic dilated bile ducts, partly filled with biliary casts in accordance with the MRI imaging ( Fig.4). These findings further supported the diagnosis of systemic sclerosis due to severe postnatal respiratory insufficiency and circulatory problems.

Intraoperative cholangioscopy enables direct visualization of the biliary tract and is evaluated for stone clearance during cholecystectomy [1, 2]. Single-operator cholangioscopy has developed as a standardized procedure during ERCP for 


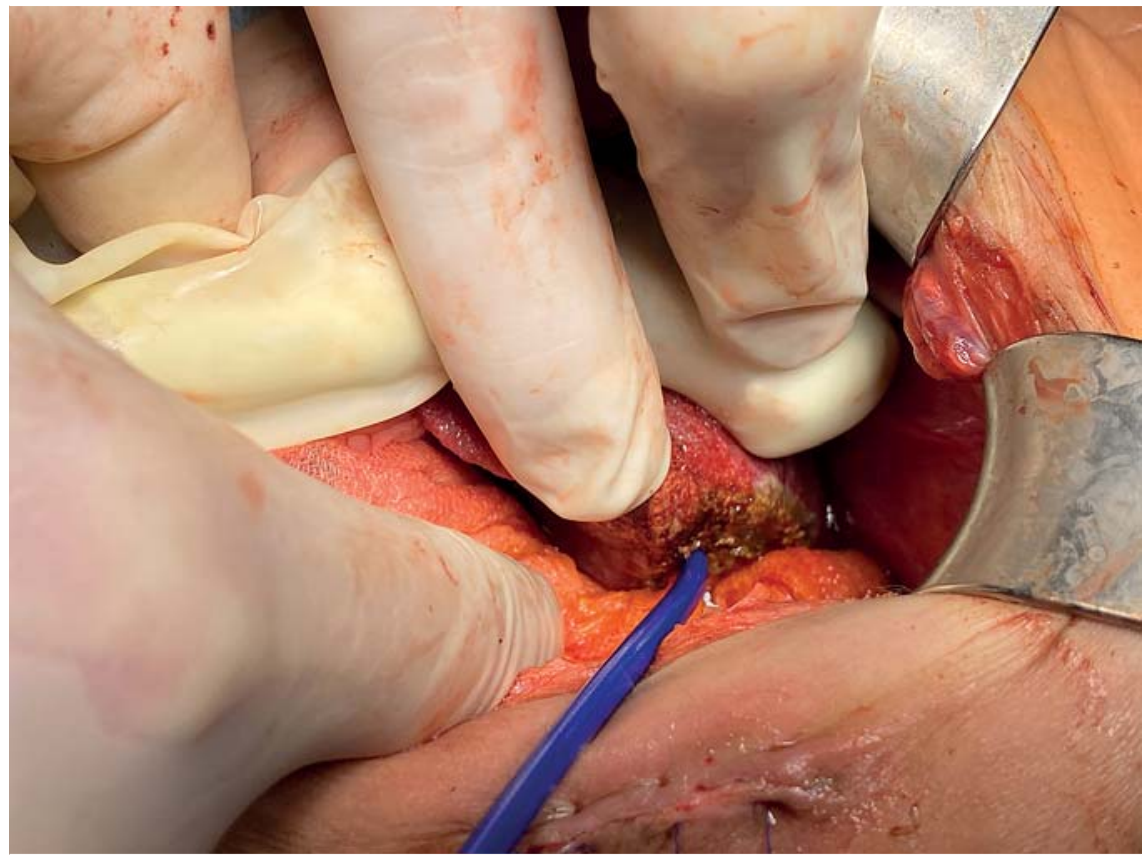

- Fig. 3 Biliary access of the SpyGlass Discover catheter via liver segment II.

indeterminate strictures and complex biliary stones [3,4]. Intraoperative access to the biliary system with the digital, single-operator cholangioscope (SpyGlass DS II system) is technically easy to achieve, but the length of the scope limits intraoperative maneuvers. A short system has been approved for percutaneous and intraoperative biliary interventions (SpyGlass Discover) that facilitates intraoperative cholangioscopy with its short scope length $(65 \mathrm{~cm})$ and angulation up to $270^{\circ}$.

We present the technical feasibility of access to any part of the biliary system, even from peripheral segments in pediatric anatomy. The insights provided by the biliary system open new horizons, bringing surgeons and endoscopists even closer.

Endoscopy_UCTN_Code_TTT_1AR_2AJ

\section{Competing interests}

Arne Kandulski receives honoraria for presentations and scientific advisories for Boston Scientific Corp. All other authors have no financial or other conflicts to declare.
The authors

Philipp Dobsch ${ }^{1}$, Stefan M. Brunner ${ }^{2}$, Birgit Knoppke $^{3}$, Hans J. Schlitt ${ }^{2}$, Arne Kandulski ${ }^{1}$

1 Department and Outpatients' Department of Internal Medicine I, University Hospital Regensburg, Germany

2 Department of Surgery, University Hospital Regensburg, Germany

3 University Children's Hospital Regensburg (KUNO), Regensburg, Germany

\section{Corresponding author}

\section{Philipp Dobsch, MD}

Department and Outpatients' Department of Internal Medicine I, University Hospital Regensburg, Franz-Josef-Strauß-Allee 11, 93053 Regensburg, Germany philipp.dobsch@gmx.de

\section{References}

[1] Manes G, Paspatis G, Aabakken L et al. Endoscopic management of common bile duct stones: European Society of Gastrointestinal Endoscopy (ESGE) guideline. Endoscopy 2019; 51: 472-491

[2] Lyu Y, Cheng Y, Li T et al. Laparoscopic common bile duct exploration plus cholecystectomy versus endoscopic retrograde cholangiopancreatography plus laparoscopic cholecystectomy for cholecystocholedo-

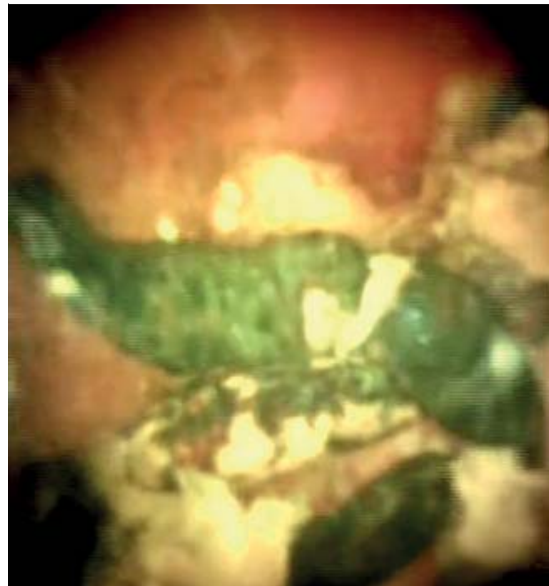

-Fig. 4 Biliary casts in a cystic dilated segment confirming the diagnosis of secondary sclerosing cholangitis.

cholithiasis: a meta-analysis. Surg Endosc 2019; 33: 3275-3286

[3] Gerges C, Beyna T, Tang RSY et al. Digital single-operator peroral cholangioscopyguided biopsy sampling versus ERCP-guided brushing for indeterminate biliary strictures: a prospective, randomized, multicenter trial (with video). Gastrointest Endosc 2020; 91: 1105-1113

[4] Bokemeyer A, Gerges C, Lang D et al. Digital single-operator video cholangioscopy in treating refractory biliary stones: a multicenter observational study. Surg Endosc 2020; 34: 1914-1922

\section{Bibliography}

Endoscopy 2022; 54: E234-E235

DOI 10.1055/a-1494-2854

ISSN 0013-726X

published online 8.6.2021

(c) 2021. Thieme. All rights reserved.

Georg Thieme Verlag KG, Rüdigerstraße 14, 70469 Stuttgart, Germany 